\title{
The Interleukin 8 Expression and its Possible Relationship with Degenerated and Injured Human Intervertebral Discs
}

\section{Basit Saleem Qazi ${ }^{1}$, Tang Kai ${ }^{1 *}$ and Asma Saleem Qazi}

${ }^{1}$ Department of Orthopedic Surgery Spine Unit, First Affiliated Hospital of Dalian Medical University, 222 Zhongshan Road, Dalian, Liaoning 116011, PR China ${ }^{2}$ Department of Pathology and Pathophysiology, Dalian Medical University, 9 West Section Lvshun South Road, Lvshun District, Dalian, Liaoning 116044, PR China

\begin{abstract}
Purpose: Cervical and Lumbar degenerative disc diseases (DDD) are a common disease of advanced age characterized by progressive changes in the intervertebral disc and associated structures. There have been great efforts for years to explain its pathophysiological mechanism(s). This study aims to provide the expression of IL-8 in a population of patients with lumbar disc herniation, cervical stenosis and vertebral fracture.
\end{abstract}

Material and methods: We compared the level of IL-8 expression in the non-degenerated and degenerated intervertebral disc samples obtained from patients who underwent surgery for vertebral fracture (non degenerated disc), lumbar disc herniation and cervical stenosis (degenerated disc), whose clinical and radiological features were suggestive of disc degeneration. IL-8 expression was studied by using the western blot, immunohistochemistry and enzyme linked immune absorbent assay methods. This study includes comparison of IL-8 concentration in groups based on patient's age and diagnosis.

Results: Significantly higher levels of IL-8 expressions were found in patient with advance age, more in vertebral fracture as compared to lumbar disc herniation and cervical stenosis patients.

Conclusion: The findings suggest that both local inflammatory responses occur in lumbar disc herniation, cervical stenosis and vertebral fracture patients. Using specific cytokines either by local or systemic application may reverse the degenerative process.

Keywords: Interleukin 8; Intervertebral disc degeneration; Cervical stenosis; Lumbar disc herniation; Vertebral fracture

Abbreviations: IL: Interleukin; DDD: Degenerative Disc Disease; IVD: Intervertebral Disc; VF: Vertebral Fracture; LDH: Lumbar Disc Herniation; CS: Cervical Stenosis; WB: Western Blot; IHC: Immunohistochemistry; ELISA: Enzyme Linked Immunosorbent Assay; Ab: Antibody; NP: Nucleus Pulposus; H\&E: Hematoxylin and Eosin; EDTA: Ethylenediaminetetraacetic Acid; BSA: Bovine Serum Albumin; RIPA: Radio Immunoprecipitation Assay; PMSF: Phenylmethylsulfonyl Fluoride; AP: Ammonium Persulphate

\section{Introduction}

In recent years, attention has begun to focus on the cellular and molecular activity of intervertebral disc tissue in the search for an understanding of role of interleukins in the pathogenesis of intervertebral disc (IVD). It has been shown that degenerated disc synthesis several pro inflammatory mediators and cytokines. The involvement of immune system in the pathogenesis of intervertebral disc is known but the current data is insufficient to explain its cytokine involvement. Interleukin- 8 has been recognized to have antiinflammatory activity in infection, inflammation, and cancer [1]. The inflammatory stimulus triggers its release from several known cells and it plays important role in inflammation and wound healing $[2,3]$.

To date, there have been no studies to focus on interleukin 8 (IL-8) productions in lumbar disc herniation (LDH), cervical stenosis (CS) and vertebral fracture (VF) patients using immunohistochemistry (IHC), western blot (WB) and enzyme linked immune absorbent assay (ELISA). We have therefore compared levels of production of the IL-8 in the above mentioned group.

The mechanism of degenerative disc disease is still unclear [4]. The research data available on degenerative disc disease is insufficient to determine its etiology and pathophysiology [5]. The production of proinflammatory mediators and cytokines is already known from the patients underwent dicstectomy [6,7].
It is important to identify changes in protein expression, locations and regulation mechanism in order to identify protein biomarkers involved in IVD pathogenesis, their roles and mechanism by which they participate in DDD. Several proteins are known to play their role in IVD disease pathogenesis and still many proteins are needed to be located. The complex nature of human intervertebral disc pathogenesis mechanism poses difficulties in both design and interpretation of experiments to unveil the mechanisms causing the process.

In this study we try to investigate that in humans, production of cytokine IL-8 can induce cellular changes in lumbar disc degeneration, cervical stenosis and normal disc (collected from vertebral body fracture patients). To date, however, there are no clear and widely accepted definitions for disc degeneration. To search the exact location of their expression we used methods like WB, ELISA and IHC to analyze our hypothesis. ELISA analysis was done to quantify the concentration of the protein specifically. IHC was done to localize IL-8 production in the human IVD and a comparison was done for the level of production of IL- 8 in degenerated and non degenerated human IVD from the disc samples obtained from patients undergoing surgeries for CS, VF and LDH.

\section{Characteristics of subjects}

A total of 50 patients, including 7 patients with CS 6 patients with

*Corresponding author: Kai Tang, Department of Orthopedic Surgery Spine Unit First Affiliated Hospital of Dalian Medical University, 222 Zhongshan Road, Dalian, Liaoning 116011, PR China, Tel: +86-15541118829; Fax: +86-411-83622844; E-mail:mpbj_gr8@yahoo.com

Received February 23, 2013; Accepted April 25, 2013; Published April 27, 2013

Citation: Qazi BS, Kai T, Qazi AS (2013) The Interleukin 8 Expression and its Possible Relationship with Degenerated and Injured Human Intervertebral Discs. J Spine 2: 135. doi:10.4172/2165-7939.1000135

Copyright: ( 2013 Qazi BS, et al. This is an open-access article distributed under the terms of the Creative Commons Attribution License, which permits unrestricted use, distribution, and reproduction in any medium, provided the original author and source are credited. 
VF and 29 patients with LDH were evaluated in this study. Table 1 shows relevant subject characteristics, including age, diagnosis, sex and histological grade. The age distribution was not the same among VF, $\mathrm{CS}$ and $\mathrm{LDH}$ patients. The mean ages of the CS, VF and LDH patients were 53, 69 and 45 years old, respectively.

\section{Materials and Methods}

\section{Subject collection}

50 Patients whose clinical and radiological features were suggestive of cervical and lumbar degenerative disc disease and underwent surgery were selected; non-degenerated intervertebral disc (normal) samples were collected from vertebral fracture patients. All specimens were washed in PBS buffer to remove the blood. Each specimen was labeled carefully, checked twice and placed into polypropylene tubes. All specimens were transferred from operation theatre to the laboratory on ice immediately after their excision and stored at $-80^{\circ} \mathrm{C}$ until further analysis. All discs were lumbar and cervical in origin and the ages of the patients ranged from 18 to 91 years (mean 50 years). Patients were selected on the basis histological grades of degeneration. Lumbar disc herniation and cervical stenosis patients had radiating leg and arm pain respectively.

Optical density was measured with an ELISA plate reader (Gene Company Ltd E1x808) at a wavelength of $450 \mathrm{~nm}$. Absolute values of IL-8 concentration in the supernatant were determined on the basis of the standard curve constructed from the solution containing known quantities of IL-8.

\section{Exclusion criteria}

We excluded patients with tumors, infections, previous lumbar/ cervical surgery and those who had an epidural injection of corticosteroids within six months of operation.

\section{Sample collection}

Human IVD samples were obtained from the patients undergoing surgery for lumbar disc herniation, cervical stenosis and vertebral body fracture. All samples were nucleus pulpous in origin. Samples were collected with permission of the patient or relatives. Ethics committee approval was given by Department of Ethics First Affiliated Hospital of Dalian Medical University and Clinical Research Center of Dalian Medical University.

\section{Treatment of tissue specimens}

A sample of nucleus pulpous was fixed and processed into paraffin wax. All the samples were decalcified in ethylenediaminetetraacetic acid (EDTA) to remove the bone as EDTA decalcification does not affect detectable levels of samples [8] as compared to snap-frozen tissue. H\&E staining was done to score the degree of morphological degeneration according to Norbert Boos classification for grading age related histological changes in IVD [9]. This scoring system provided a representation of the grade of degeneration within a disc: scores of 0 to 22 were assigned according to degree of degeneration.

\section{Sample preparation}

The lysate method was used after the histogens were unfastened at room temperature. They were smashed in mortar and pestle on ice using RIPA and PMSF (BioTek PP1901 $50 \mathrm{ml}$ PP1902 $100 \mathrm{ml}$ ) according to manufacturer's instruction. The extract was then centrifuged at 14,000 $\mathrm{rpm}$ for $10 \mathrm{~min}$ at $4^{\circ} \mathrm{C}$, the supernatant was collected and placed in tubes at $4^{\circ} \mathrm{C}$ for $60 \mathrm{mins}$ and then stored at $-80^{\circ} \mathrm{C}$ until further analysis.
The protein concentration was determined by Bradford assay using $1 \mathrm{mg} / \mathrm{ml}$ bovine serum albumin (BSA) as standard. Protein solution was assayed in duplicates in 96 well plates and the absorbance was measured at $450 \mathrm{~nm}$. The optical density (O.D. value) was obtained by Gene Company Ltd EIx808 (Hong Kong Gene Company. Ltd, Hong Kong).

\begin{tabular}{|c|c|c|c|c|c|}
\hline $\begin{array}{l}\text { Laboratory } \\
\text { number }\end{array}$ & Age (Y) & Sex & Clinical Diagnosis & Disc Level & $\begin{array}{c}\text { Histological } \\
\text { Grade }\end{array}$ \\
\hline B1 & 73 & Female & LDH & L4-S1 & 13 \\
\hline B2 & 73 & Female & LDH & L5-S1 & 12 \\
\hline B3 & 43 & Male & LDH & L5-S1 & 9 \\
\hline B4 & 42 & Female & $\mathrm{LDH}$ & L5-S1 & 10 \\
\hline B5 & 24 & Male & LDH & L5-S1 & 9 \\
\hline B6 & 54 & Female & LDH & L4-L5 & 9 \\
\hline B7 & 61 & Male & LDH & L4-S1 & 11 \\
\hline B8 & 48 & Male & LDH & L5-S1 & 8 \\
\hline B9 & 54 & Male & LDH & L4-L5 & 12 \\
\hline B10 & 65 & Male & LDH & L4-S1 & 14 \\
\hline B11 & 44 & Male & LDH & L4-L5 & 8 \\
\hline B12 & 40 & Female & LDH & L4-L5 & 12 \\
\hline B13 & 43 & Female & LDH & L5-S1 & 9 \\
\hline B14 & 51 & Female & LDH & L4-L5 & 9 \\
\hline B15 & 27 & Male & LDH & L4-L5 & 5 \\
\hline B16 & 59 & Male & CS & C4-C5 & 10 \\
\hline B17 & 18 & Female & LDH & L4-L5 & 5 \\
\hline B18 & 46 & Male & CS & C4-C5 & 8 \\
\hline B19 & 58 & Female & LDH & L5-S1 & 10 \\
\hline B20 & 22 & Female & LDH & L3-L4 & 6 \\
\hline B21 & 53 & Male & LDH & L4-L5 & 14 \\
\hline B22 & 51 & Female & CS & C5-C6 & 13 \\
\hline B23 & 60 & Male & LDH & L4-S1 & 12 \\
\hline B24 & 60 & Male & LDH & L4-L5 & 13 \\
\hline B25 & 47 & Male & CS & C5-C6 & 11 \\
\hline B26 & 70 & Male & $\mathrm{LDH}$ & L3-L5 & 11 \\
\hline B27 & 44 & Female & $\mathrm{LDH}$ & L4-L5 & 12 \\
\hline B28 & 67 & Male & $\mathrm{LDH}$ & $14-15$ & 15 \\
\hline B29 & 18 & Male & $\mathrm{LDH}$ & L5-S1 & 7 \\
\hline B30 & 26 & Female & VF & L2 & 7 \\
\hline B31 & 52 & Male & CS & C4-C6 & 11 \\
\hline B32 & 65 & Male & CS & C3-C7 & 12 \\
\hline B33 & 33 & Male & LDH & L5-S1 & 9 \\
\hline B34 & 66 & Male & LDH & L5-S1 & 9 \\
\hline B35 & 41 & Male & LDH & L4-L5 & 12 \\
\hline B36 & 52 & Female & LDH & L4-L5 & 13 \\
\hline B37 & 48 & Female & CS & C4-C5 & 7 \\
\hline B38 & 50 & Female & LDH & L4-L5 & 10 \\
\hline B39 & 38 & Female & $\mathrm{LDH}$ & L5-S1 & 8 \\
\hline B40 & 51 & Male & $\mathrm{LDH}$ & L5-S1 & 15 \\
\hline B41 & 24 & Female & $\mathrm{LDH}$ & L5-S1 & 8 \\
\hline B42 & 78 & Female & VF & L2 & 14 \\
\hline B43 & 74 & Female & LDH & L4S1 & 16 \\
\hline B44 & 38 & Male & VF & L3 & 10 \\
\hline B45 & 91 & Female & VF & L2 & 16 \\
\hline B46 & 90 & Female & VF & L2 & 15 \\
\hline B47 & 90 & Male & VF & L3 & 17 \\
\hline B48 & 19 & Female & LDH & L5-S1 & 6 \\
\hline B49 & 21 & Female & LDH & L4-L5 & 7 \\
\hline B50 & 23 & Male & LDH & L5-S1 & 6 \\
\hline
\end{tabular}

VF: Vertebral Fracture; CS: Cervical Stenosis; LDH: Lumbar Disc Herniation

Table 1: Details of patients used for IHC, WB and ELISA analysis. 


\section{Immunohistochemical analysis}

Immunohistochemistry analysis was done according to previously published protocol, [10] it localized IL-8 within the 50 disc samples as described in table 1. Prostatic cancer tissue section was selected as a positive control for IL-8 [11]. $5 \mu \mathrm{m}$ wax sections were re waxed and rehydrated. After washing, heat-induced epitope retrieval was performed using a pressure cooker. Sections were incubated overnight at $4^{\circ} \mathrm{C}$ with IL-8 polyclonal primary antibody (1:50 dilution SC7922 Santa Cruz Biotechnologies, Santa Cruz, CA, USA). Negative controls in which goat IgGs (Dako, Cambridgeshire, UK) replaced the primary antibody (at an equal protein concentration) were used. Disclosure of secondary antibody binding was by Goat Anti-rabbit IgG-HRP (Santa Cruz Biotechnologies, Santa Cruz, CA, USA; catalogue \# sc-2004) for $30 \mathrm{mins}$ at room temperature. Histological sections were stained with Mayer's haematoxylin (Raymond A Lamb, East Sussex, UK), dehydrated, and mounted in XAM (BDH, Liverpool, UK). Table 1 shows Details of patients used for IHC, WB and ELISA analysis.

\section{Enzyme-linked Immunosorbent Assay (ELISA) for IL-8}

The IVD tissue IL- 8 concentrations in both cervical and lumbar region were assessed in the CS, VF and LDH groups. IL-8 levels were measured as specified by the manufacturer with a sandwich enzymelinked immunosorbent assay (ELISA) (Genentech) as described previously [12]. In this assay, IL-8 rabbit polyclonal antibody (sc7922 Santa Cruz Biotechnologies, CA, USA) was used as the primary capture antibody $(\mathrm{Ab})$ and Goat Anti-rabbit IgG-HRP (sc-2004 Santa Cruz Biotechnologies, Santa Cruz, CA, USA) was used as the secondary $\mathrm{Ab}$ for recognition of the antigen. Standards and cytokine controls were included. The optical density was measured at $450 \mathrm{~nm}$ on a 96-well microplate reader (Biotek EL808 Gene Company Ltd, US) using GeneTek software (Genetek Company). A standard curve was plotted, and an IL8 concentration in each sample was determined by interpolation from the standard curve. The data represents the mean of three independent experiments \pm SEM. Absolute values of IL-8 concentration in the supernatant were determined on the basis of the standard curve constructed from the solution containing known quantities of IL-8.

\section{Western blot analysis}

The protein concentration of the total lysate was determined using a Bradford protein assay (Bio-Rad Laboratory, Richmond, CA, USA) then separated on $15 \%$ SDS-polyacrylamide gels and subsequently transferred to PVDF Membrane 0.2nm (Santa Cruz N8017) at 330 $\mathrm{mA}$ for $2 \mathrm{~h}$ using a transfer buffer containing $25 \mathrm{mM}$ Tris, $192 \mathrm{mM}$ glycine, and $20 \%$ methanol (pH 8.3). For immunoblotting, membranes were blocked with $10 \%$ nonfat dried milk (Santa Cruz 2324) in Trisbuffered saline (TBS) for $1 \mathrm{~h}$. Primary antibody IL-8 (H-60) rabbit polyclonal antibody (Santa Cruz Biotechnologies USA; sc-7922) was applied at 1:800 at $4^{\circ} \mathrm{C}$ overnight. After washing the membranes 3 times for $30 \mathrm{~min}$ with PBS, they were incubated with secondary antibody Anti-rabbit IgG-HRP (Santa Cruz Biotechnologies, USA; sc-2004) at 1:10,000 for $1 \mathrm{~h}$. Blots were then washed for $1 \mathrm{~h}$ at room temperature and then washed 3 times for $30 \mathrm{~min}$ with PBS. GAPDH was run as an internal control. Next, the immune complexes were detected using the ECL system (Amersham Pharmacia Biotech, Pisctaway, NJ) and exposed to photographic film (Fisher Scientific Company, Canada). Densitometry was then performed using a Bio-Rad (Hercules, CA, USA) 700 flatbed scanner and Molecular Analyst Software (Bio-Rad). The films and membranes were then scanned at 600 dots per inch using light transmittance, after which pixel volume analysis was performed on the appropriate bands. Scanning of the Western blots revealed that the curve was linear in the range used for each antibody.

\section{Statistical analysis}

The data obtained was analyzed statistically by SPSS Version 20.0 for Windows 7 (SPSS Inc, IL, USA). All data in the text is expressed as

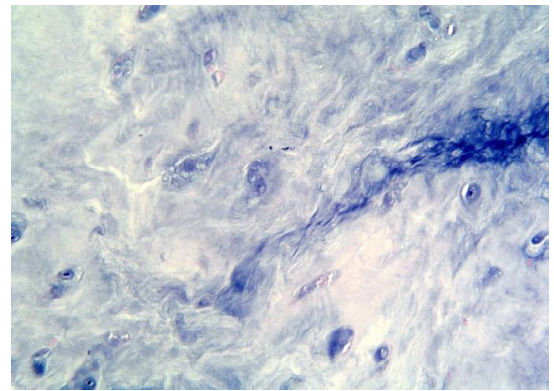

Cell Death

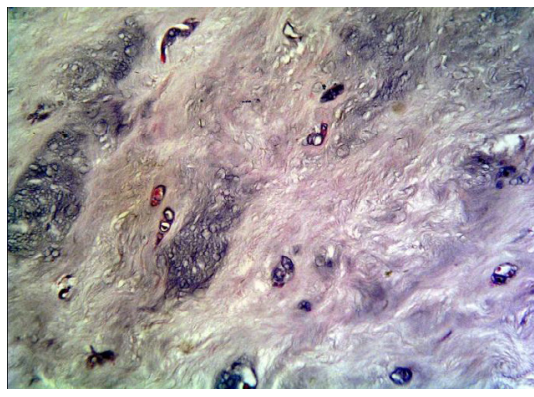

Mucous Degeneration

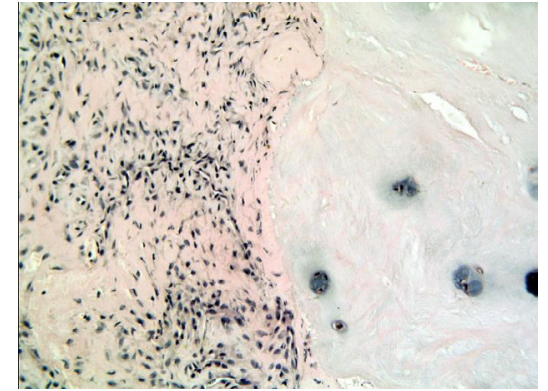

Granular Changes

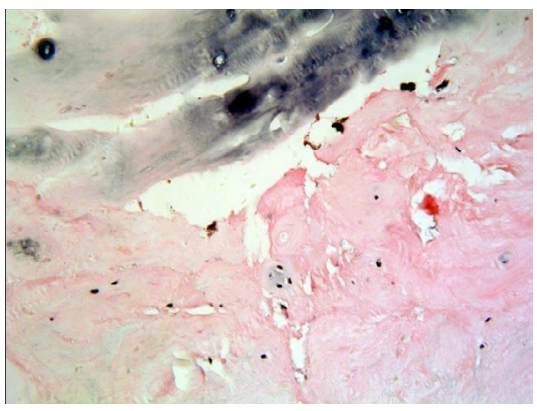

Tears and Cleft

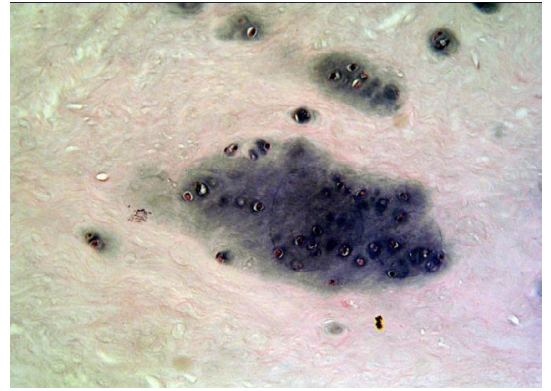

Cell Cluster Formation (huge clone)

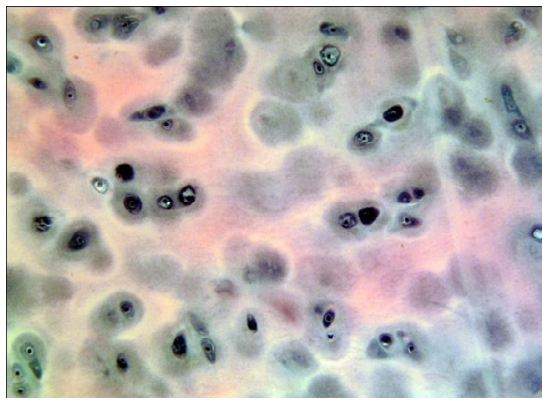

Normal Disc

Figure 1: Histopathological findings of the intervertebral disc stained with hematoxylin and eosin. 
the mean \pm SD. Two group comparisons were evaluated using paired or unpaired T-tests. Multiple comparisons were analyzed by ANOVA atpting $\mathrm{p}<0.05$ as the level of significance $[13,14]$.

\section{Results}

\section{Histopathological examination}

Figure 1 shows the histopathological findings of the intervertebral disc stained with hematoxylin and eosin.

\section{Immunohistochemical Images}

Figure 2 shows examples of Immunohistochemical staining for IL-8 in IVD (C, D). Positive control (A) showing immunopositivity in prostate cancer tissue IgG controls (B) were all negative. Immunopositivity is revealed by brown staining $(C, D)$.

\section{Image analysis}

All immunohistochemical and H\&E staining slides were visualized using the Leica RMDB research microscope and images were captured using a digital camera and the Bioquant Nova image analysis system. (magnification: $\times 20$ ) Within each area, 200 cells were counted and the number of immunopositive cells was expressed as a proportion of this.

Immunopositivity is revealed by brown staining. In non-degenerate discs, no cell clusters were seen and little immunopositivity was observed in the single cells. In degenerate discs, a large number of cell clusters were observed, which were predominately immunopositive. Bars $=570 \mu \mathrm{m}$.

The graphs are representing the numbers of cells with immunopositivity for IL-8, according to diagnosis and age group. Data is represented as means $\pm \mathrm{SD}$. P was significant for diagnosis and age group at $\mathrm{p}<0.05$ (Figure 3 ).

The graphs are representing the concentration of IL-8 determined by ELISA in diagnosis and age group (Figure 4). Data is represented as means \pm SD. P significant for the diagnosis and age group at $\mathrm{p}<0.05$.
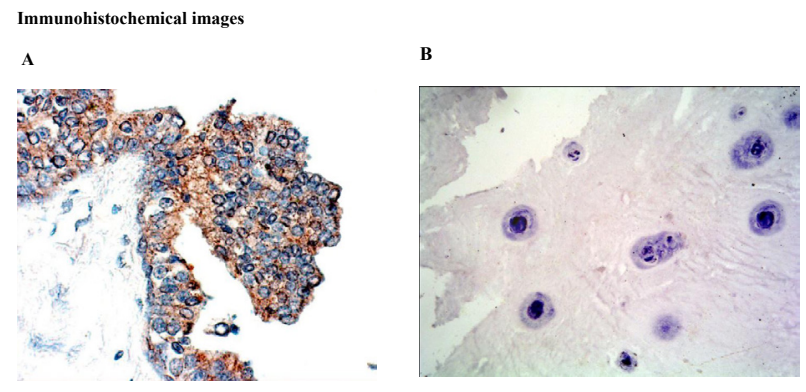

C
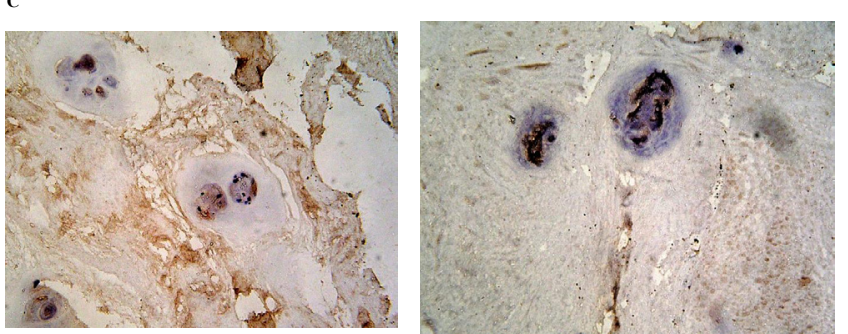

Figure 2: Examples of Immunohistochemical staining for IL-8 in IVD (C, D). Positive control (A) showing immunopositivity in prostate cancer tissue. IgG controls $(B)$ were all negative. Immunopositivity is revealed by brown staining (C, D).

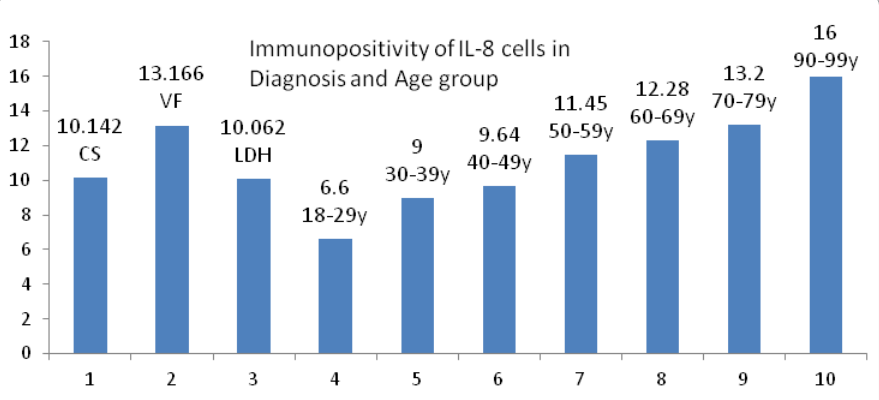

Figure 3: The graphs are representing the numbers of cells with immunopositivity for IL-8, according to diagnosis and age group. Data is represented as means \pm SD. $P$ was significant for diagnosis and age group at $p<0.05$.

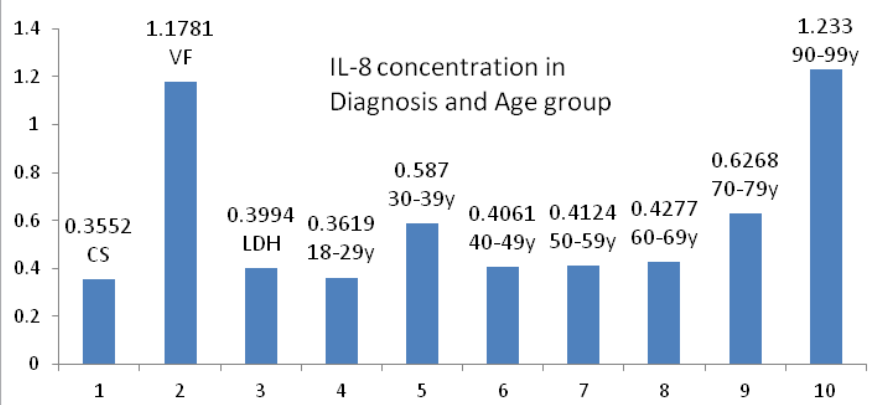

Figure 4: The graphs are representing the concentration of IL-8 determined by ELISA in diagnosis and age group (Figure 4). Data is represented as means \pm SD. $P$ significant for the diagnosis and age group at $p<0.05$.

\section{ELISA interpretation}

IL8 chemokine levels in supernatants were measured by solidphase sandwich ELISA. Data are shown as $\mathrm{pg} / \mathrm{ml}$ concentration. At the end of the incubation, IL- 8 in the medium was measured by ELISA. Values were normalized to total cell protein and represent the average \pm standard deviation (error bar) of triplicate samples ( $p<0.05$ for all concentrations of IL8 in the intervertebral disc samples). Similar results were seen in two other independent experiments.

\section{Expression of IL-8 by Western blot analysis}

Figure 5 shows the expression of IL- 8 by Western blot analysis.

Figure 6 shows the western blot analysis presenting expression of IL-8 $\mathrm{x}$ (was conducted using samples as mentioned in Table 1)x. There was statistical difference in the expression of IL- 8 in the diagnosis and age group at $\mathrm{p}<0.05$.

Western blot analysis presenting expression of IL-8 $\mathrm{x}$ (was conducted using samples as mentioned in Table 1)x. There was statistical difference in the expression of IL- 8 in the diagnosis and age group at $\mathrm{p}<0.05$.

\section{Western blot analysis and relative intensities of the expression of IL-8}

Western blots (Fig 5) of VF, CS and LDH and GAPDH (each band has number which indicates the sample number in table 1). Disc tissue proteins $(50 \mu \mathrm{l})$ from VF, CS and LDH patients were loaded in each lane. Quantities represented by gel bands are expressed as intensities relative to GAPDH. Data represent the means \pm SD $(\mathrm{CS}=62.78 \% \pm$ $0.2542, \mathrm{VF}=96.51 \% \pm 0.01, \mathrm{LDH}=60.64 \% \pm 26.72$, male $=62.64 \% \pm$ 24.714 , female $=72.61 \% \pm 22.1719,18-49 \mathrm{yrs}=60.07 \% \pm 23.61381,50-$ $91 \mathrm{yrs}=78.02 \% \pm 23.64617)$. 


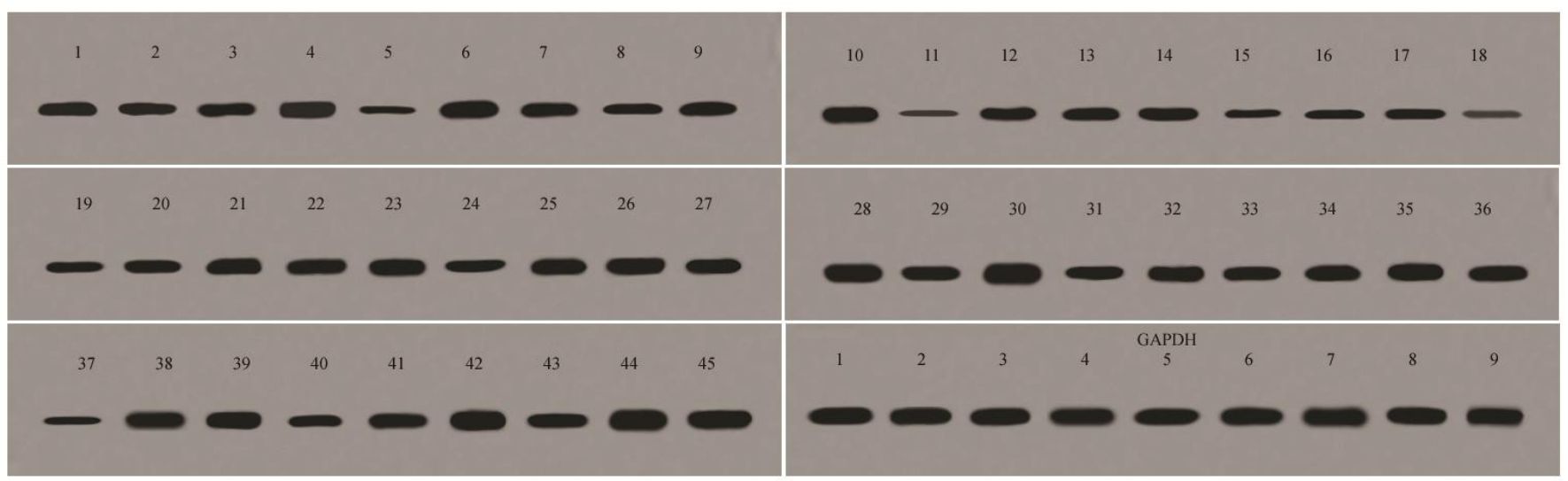

Figure 5: Expression of IL-8 by Western blot analysis.

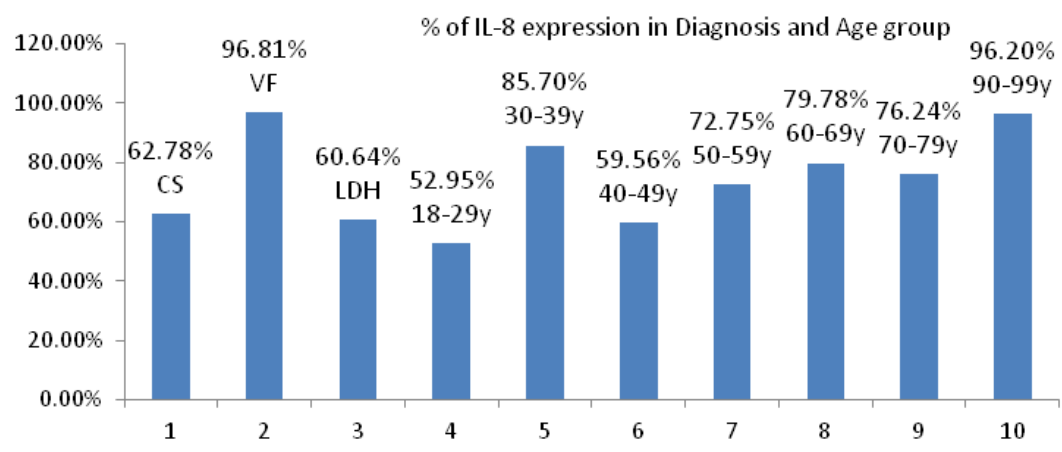

Figure 6: Western blot analysis presenting expression of IL-8 $x$ (was conducted using samples as mentioned in Table 1)x. There was statistical difference in the expression of IL-8 in the diagnosis and age group at $p<0.05$.

\section{Discussion}

There was a statistically significant difference between levels of production of IL- 8 between the diagnosis group ( $\mathrm{p}=0.04$ (WB) $\mathrm{p}=0.05$ (IHC)) and the age group ( $\mathrm{p}=0.0000000148$ (IHC)).

The high levels of pro inflammatory mediator found in disc tissue from patients undergoing surgery suggest that production of pro inflammatory mediators within the IVD may be a major factor in the genesis of a painful cervical and lumbar disc conditions.

The sequel of disc degeneration are among the leading causes of functional incapacity in both sexes and are a common source of chronic disability in the working years. Disc degeneration involves structural disruption and cell mediated changes in composition. Mechanical, traumatic, nutritional, and genetic factors all may play a role in the cascade of disc degeneration, albeit to variable degree in different individuals. Immunoreactivity for the IL- 8 was seen in degenerate and non degenerate IVDs. The immunostaining was generally restricted to the nucleus of native disc cells in normal and degenerate discs. Staining was particularly prominent in the nucleus of the cell clusters formed by few, several and many cells. No significant difference was observed between the proportions of cells in the NP and IAF reacting for IL-8. Immunopositive cells were more frequent in the vertebral fracture group than in cervical stenosis and lumbar disc herniation group. Moreover immunopositive cells were more in specimens with higher degeneration scores and advanced age. No immunopositivity was observed in the matrix of the IVDs or in blood vessel. Although cells in the all group did show reactivity, the proportion was always significantly different in diagnosis and age groups (All targets $\mathrm{p}<0.05$ )

In addition, immunopositivity for these proteins increased with degree of degeneration. The minimum expression was mostly shown by lower age and by patients operated my microscopic endoscopic disctectomy. The sample showing lower expression was $18.80 \%$, $19.32 \%, 43.59 \%, 43.40 \%$ and the highest expression was $86.94 \%$, $95.44 \%, 85.04 \%, 85.36 \%, 86.2 \%, 86.21 \%, 96.76 \%, 96.83 \%$ and $98.22 \%$.

There might be a positive correlation of IL- 8 in progression and development of degeneration in intervertebral disc considering the IL-8 expressions as mentioned in figure 4. However higher expression in vertebral fracture suggests its role in fracture healing. These findings suggest that degenerate discs which cause pain in cervical stenosis and lumbar disc herniation group differ at a cellular and molecular level from those with vertebral fracture group. The reasons for increased production of IL-8 in patients with cervical and lumbar conditions and vertebral fractures are unknown. A recent study has shown that few inflammatory cells are found in these discs [15] and therefore the source of the mediators must be cells from the nucleus pulposus itself. It is known that such tissue can produce a range of proinflammatory cytokines [16,17]. We suggest as some discs degenerate the cells of the nucleus pulposus may be exposed to a proinflammatory stimulus leading to a form of inflammatory degeneration which gives rise to low back pain in lumbar conditions and neck and radiating arm pain in cervical conditions. The nature of this stimulus is currently unknown. Difference in expression at cervical and lumbar region as concluded by 3 different analyses might link their different roles in development and 
progression of degeneration in intervertebral disc where they can also differ at cellular and molecular level. Our research has mainly focused on the IL-8 expression in lumbar disc herniaton, cervical stenosis and vertebral fracture patients. It was hypothesized that there is a local production of IL- 8 in human intervertebral disc and the quantity of IL-8 expression increase in trauma and degeneration with tends to increase with age and degeneration level. Our study confirms these findings. It has been recently shown that human nucleus pulposus produces IL-8 [18]. There are no previous studies in the literature comparing the levels of production of IL-8 in degenerate and non degenerate disc.

We have observed more IL- 8 production by intervertebral discs from patients with vertebral fracture than with disc from lumbar disc herniation and cervical stenosis patients with radiating leg and arm pain respectively. Figures 1, 2 and 4 illustrate the difference between the groups. The rate of production of IL- 8 in the vertebral fracture group and increasing age group are much higher than others, further underlining the differences between them.

Discs which cause low back pain have higher concentrations of sensory nerves than are seen in those which do not cause such pain $[19,20]$. The sensory nerves in the former are found in the endplates and in the nucleus pulpous and lose their normal relationship with blood vessels. The in growth of nerves into degenerate discs which cause low back pain may be mediated by chemotactic substances released by the degenerating disc [21].

\section{Conclusion}

All the results indicate that IL- 8 is produced in the degenerate and non degenerate IVD. It is synthesized by native disc cells, and represents the changes seen during disc degeneration. The etiology of pain as the symptom of degenerative disease is complex and appears to be a combination of mechanical deformation and the presence of inflammatory mediators. Unlike acute injury, degenerative disease cause slow but progressive changes in the intervertebral disc, facet joints and posterior ligamentous structures that eventually may lead to spondylosis and/or spondylolistesis [22]. Many studies have focused on the inflammatory responses, such as cellular infiltrates and proinflammatory cytokines, associated with lumbar disc herniation [23]. The effect of inflammatory responses on the development of radiculopathy has also been studied [24]. In addition, antibodies and immunoglobulins have been detected in patients with lumbar disc herniation [25].

In recent years, attention has begun to focus on the cellular and molecular activity of intervertebral disc tissue in the search for an understanding of the mechanisms of intervertebral disc disease.

The linear correlation of IL-8 supports the theory that individual discs can produce an inflammatory response and suggests that the stimulus provoking production of these mediators is the same. The high levels of pro-inflammatory mediator found in disc tissue from patients undergoing surgery for vertebra fracture suggest that production of pro-inflammatory mediators within the nucleus pulposus may be a major factor in the genesis of a painful disc in traumatic fractured patients or may be IL-8 plays some role in bone healing that's why it rises in traumatic fractured patients. However more research is required to solve this question. Therefore, inhibiting IL-8 could be an important therapeutic target for preventing and reversing disc degeneration and enhancing IL-8 expression could promote vertebral fracture healing.

Our results support the notion that immune reactions may play an important role in the degenerative processes in lumbar degenerative disorders and understanding of the cascades involved in degeneration will improve our treatment strategies. Using specific cytokines either by local or systemic application may reverse the degenerative process. Controlling the degeneration will provide benefit to the patients, treating physicians and more importantly decrease the related disability and cost of the treatment of this chronic disease. In summary, this study demonstrates IL-8 chemokine secretion in human IVD.

\section{Acknowledgements}

The work has undertaken in Sino United Kingdom Centre of Regenerative Medicine, First Affiliated Hospital of Dalian Medical University. The authors wish to thanks Prof Dr. Jill P G Urban and Prof. Dr. Yu Jing, Laboratory of Physiology, Oxford University for their suggestions and help during this research and thanks to the surgery team of Orthopedics Spine Surgery Department, First Affiliated Hospital of Dalian Medical University for supplying tissue samples.

\section{References}

1. Qazi BS, Tang K, Qazi A (2011) Recent advances in underlying pathologies provide insight into interleukin-8 expression-mediated inflammation and angiogenesis. Int J Inflam 2011: 908468.

2. Matsushima K, Oppenheim JJ (1989) Interleukin 8 and MCAF: novel inflammatory cytokines inducible by IL 1 and TNF. Cytokine 1: 2-13.

3. Dobreva I, Waeber G, James RW, Widmann C (2006) Interleukin-8 secretion by fibroblasts induced by low density lipoproteins is p38 MAPK-dependent and leads to cell spreading and wound closure. J Biol Chem 281: 199-205.

4. Mooney V (1987) Presidential address. International Society for the Study of the Lumbar Spine. Dallas, 1986. Where is the pain coming from? Spine (Phila Pa 1976) 12: 754-759.

5. Buckwalter JA (1995) Aging and degeneration of the human intervertebral disc Spine (Phila Pa 1976) 20: 1307-1314

6. Kang JD, Georgescu HI, Mclntyre-Larkin L, Stefanovic-Racic M, Evans CH (1995) Herniated cervical intervertebral discs spontaneously produce matrix metalloproteinases, nitric oxide, interleukin-6, and prostaglandin E2. Spine (Phila Pa 1976) 20: 2373-2378.

7. Rand N, Reichert F, Floman Y, Rotshenker S (1997) Murine nucleus pulposusderived cells secrete interleukins-1-beta, -6 , and -10 and granulocytemacrophage colony-stimulating factor in cell culture. Spine (Phila Pa 1976) 22 2598-2601.

8. Walsh L, Freemont AJ, Hoyland JA (1993) The effect of tissue decalcification on mRNA retention within bone for in-situ hybridization studies. Int J Exp Pathol 74: $237-241$

9. Boos N, Weissbach S, Rohrbach H, Weiler C, Spratt KF, et al. (2002) Classification of age-related changes in lumbar intervertebral discs: 2002 Volvo Award in basic science. Spine (Phila Pa 1976) 27: 2631-2644.

10. Le Maitre CL, Freemont AJ, Hoyland JA (2004) Localization of degradative enzymes and their inhibitors in the degenerate human intervertebral disc. $J$ Pathol 204: 47-54.

11. Huang J, Yao JL, Zhang L, Bourne PA, Quinn AM et al. ( 2005) Differential Expression of Interleukin-8 and Its Receptors in the Neuroendocrine and NonNeuroendocrine Compartments of Prostate Cancer. Am J Pathol 166: 18071815.

12. Boylan AM, Hebert CA, Sadick M, Wong WL, Chuntharapai A (1994) Interleukin-8 is a major component of pleural liquid chemotactic activity in a rabbit model of endotoxin pleurisy. Am J Physiol 267: L137-L144.

13. Streiner DL (1996) Maintaining standards: differences between the standard deviation and standard error, and when to use each. Can J Psychiatry 41: 498502.

14. Gruber HE, Hanley EN Jr (1998) Analysis of aging and degeneration of the human intervertebral disc. Comparison of surgical specimens with normal controls. Spine (Phila Pa 1976) 23: 751-757

15. Roberts S, Menage J, Evans EH (2000) Inflammation of the intervertebral disc: an uncommon finding in discs associated with discogenic back pain. J Bone Joint Surg [Br] 82-B:Supp II: 98

16. Rand N, Reichert F, Floman Y, Rotshenker S (1997) Murine nucleus pulposusderived cells secrete interleukins-1-beta, -6 , and -10 and granulocytemacrophage colony-stimulating factor in cell culture. Spine (Phila Pa 1976) 22 2598-2601. 
Citation: Qazi BS, Kai T, Qazi AS (2013) The Interleukin 8 Expression and its Possible Relationship with Degenerated and Injured Human Intervertebral Discs. J Spine 2: 135. doi:10.4172/2165-7939.1000135

Page 7 of 7

17. Nygaard OP, Mellgren SI, Osterud B (1997) The inflammatory properties of contained and noncontained lumbar disc herniation. Spine (Phila Pa 1976) 22 : 2484-2488.

18. Burke JG, Watson RWG, McCormack D (1999) Spontaneous disc herniation resorption may be mediated by chemokines. Proceedings of the North American Spine Society, 14th Annual Meeting, Chicago 130-131.

19. Coppes MH, Marani E, Thomeer RT, Groen GJ (1997) Innervation of "painful" lumbar discs. Spine (Phila Pa 1976) 22: 2342-2349.

20. Brown MF, Hukkanen MV, McCarthy ID, Redfern DR, Batten JJ, et al. (1997) Sensory and sympathetic innervation of the vertebral endplate in patients with degenerative disc disease. J Bone Joint Surg Br 79: 147-153.

21. Tessier-Lavigne M, Placzek M (1991) Target attraction: are developing axons guided by chemotropism? Trends Neurosci 14: 303-310.
22. Cypress BK (1983) Characteristics of physician visits for back symptoms: a national perspective. Am J Public Health 73: 389-395.

23. Takahashi $H$, Suguro $T$, Okazima $Y$ (2001) Inflammatory cytokines in the herniated intervertebral disc tissue. An immunohistochemical study. Eur Spine J 10: 172-176.

24. Holm S, Mackiewicz Z, Holm AK, Konttinen YT, Kouri VP, et al. (2009) Proinflammatory, pleiotropic, and anti-inflammatory TNF-alpha, IL-6, and IL-10 in experimental porcine intervertebral disk degeneration. Vet Pathol 46: 12921300.

25. Shamji MF, Setton LA, Jarvis W, So S, Chen J, et al. (2010) Proinflammatory cytokine expression profile in degenerated and herniated human intervertebral disc tissues. Arthritis Rheum 62: 1974-1982. 